\title{
The Influence of Informed Buyers in Markets Susceptible to the Lemons Problem
}

\author{
By Philippe Mahenc* \\ JEREM, Dpt de Sciences Economiques, \\ Université de Perpignan, \\ 52 avenue de Villeneuve 66860 Perpignan Cedex, France. \\ Email : mahenc@univ-perp.fr \\ $1^{\mathrm{er}} \operatorname{mars} 2004$
}

\begin{abstract}
Résumé
I show that the presence of informed buyers is necessary but not always sufficient for producers to use prices as signals of product quality.

A sufficiently high fraction of informed buyers eliminates the lemons problem. A small fraction of informed buyers mitigates the lemons problem, provided that buyers' prior belief of high quality is sufficiently pessimistic : price reveals high quality at a signaling cost which increases with market power. However, if buyers' prior belief of high quality is optimistic when the market is poorly informed, then the lemons problem is not overcome.

Keywords : Experience Good, Quality, Signaling, Bordeaux Wine.

JEL Code : D42, D82, L15.
\end{abstract}

${ }^{*}$ JEREM, Dpt de Sciences Economiques, Université de Perpignan, 52 avenue de Villeneuve 66860 Perpignan Cedex, France. Email : mahenc@univ-perp.fr and LEERNA-INRA, Université Toulouse 1. 


\section{The Influence of Informed Buyers in Markets Susceptible to the Lemons Problem}

\section{Introduction}

Whatever the degree of competition, markets in which the producer knows the quality of his good but the buyer does not are susceptible to Akerlof's (1970) lemons problem : a low-quality good sells at the same price as a high-quality good because it is impossible for most of the buyers to tell the difference between a high and a low quality. The lemons problem is important to the food sector and to markets for products that generate less environmental harm such as organically grown agricultural products. The latter are often either experience or credence goods. Karl and Orwat (1999) or Cason and Gangadharan (2002) explicitly addresses the issue that consumers often find it difficult to identify the environmental quality of clean products. Similarly, the quality of Bordeaux grands crus can hardly be observed prior to purchase. When prices alone fail to signal quality, uninformed buyers rely on private expert opinion, public disclosure programs or the externality exerted by informed buyers to acquire information. The objective of this paper is to examine to what extent the presence of informed buyers might be used by producers to signal quality through prices.

In order to illustrate, consider the market for Bordeaux grands crus. Each year, the Bordeaux "primeur" release deals with $80 \%$ of the châteaux total 
production. While the wine is still in barrels, hence is not yet mature, the owners of the foremost châteaux set a price called "primeur" price. One special feature of this marketing strategy is that wine becomes an experience good in the sense of Nelson (1974) since full information on quality is not available to buyers at the time of purchase. Another feature is that buyers rely on expert opinion to make their purchase decisions. Figures 1 and 2 illustrate that the "primeur" release of grands crus is susceptible to Akerlof's (1970) lemons problem. The four curves that are almost superimposed in Figure 1 depict the changes in the "primeur" prices of four grands crus classified as FirstGrowth of the appellation Médoc. One can see that these four châteaux have been setting the same price since 1980 for almost all the vintages. Figure 1 might suggest that, for a given vintage, the wine quality is even regardless of the château, provided that the "primeur" price is an effective signal of quality. However, Figure 2 shows that the scores assigned in January 2002 to the four wines by Robert Parker, a famous wine expert and editor of The Wine Advocate, noticeably differ from one château to another. If the expert opinion provides accurate estimates of quality, then "primeur" prices have failed to signal quality at least for the aforementioned châteaux.

This article investigates a signaling model of price in the spirit of Milgrom and Roberts (1986) or Bagwell and Riordan (1991), which is inspired by the main features of the Bordeaux grands crus industry.

A wine is a bundle of characteristics : taste, quality, color, aroma, balance, 
aging potential, location, time, and so on. I consider two differentiated goods which differ in taste and quality. Taste is an horizontal characteristic in the sense that it differs from one buyer to another. On the other hand, quality is a vertical characteristic and so I assume that there exists a single ranking of qualities based on the expert opinion, with which all buyers agree ${ }^{1}$. In my framework, one good can be seen as a wine produced by one of the foremost châteaux dominating the Bordeaux wine industry in terms of quality, while the other good is a second wine sold by lesser known wine producers ${ }^{2}$. The superior good is more costly to produce than the other good (hence production techniques determine quality), and it endows the producer with a monopolistic position. Furthermore, the superior good is an experience good : all buyers know that its quality is higher than that of the other good, but some buyers cannot ascertain whether it is much higher or a little higher. These differences in the quality of the superior good are due to exogenous factors, that is, factors outside the control of the monopolist such as weather (hence nature also determines the quality of the superior good). The lemons problem is formally captured by the benchmark that the monopoly price of the superior product could not signal quality were all buyers uninformed. The other good is sold by a competitive fringe of small producers and its quality is perfectly known.

\footnotetext{
${ }^{1}$ Robert Parker argues that "there are specific standards of quality that full-time wine professional recognize" (quoted in Landon and Smith (1997)).

${ }^{2}$ Wine producers classified for instance as Crus Bourgeois.
} 
As a result, whatever the degree of monopoly power, the presence of informed buyers is necessary for the monopoly price to be an effective signal of quality but not always sufficient. A sufficiently high fraction of informed buyers eliminates the lemons problem by exerting a negative externality on the low-quality monopolist. These informed buyers so increase the cost of pricing for the low-quality monopolist that replicating the high-quality product price becomes unprofitable. Thus, the condition emphasized by Spence (1973) for a signal to be effective is met : the high-quality monopolist bears lower costs for signaling through price. A small fraction of informed buyers mitigates the lemons problem, provided that buyers' prior belief of high quality is sufficiently pessimistic. In the case of such a poorly informed market, the monopolist bears a signaling cost to reveal the high quality by distorting his price above the full information level. However, if buyers' prior belief of high quality is optimistic when the market is poorly informed, then signaling the true quality is more costly than accepting mimicry for the high-quality monopolist, and so uninformative prices prevail.

Furthermore, this work evaluates the impact of the monopolist's market power on price signaling. The main idea is that more market power increases the signaling cost to reveal high quality because the low-quality monopolist finds mimicry more attractive : the more market power, the lower the loss of buyers who refuse to buy at a higher mimicking price.

While the present model is closely related to the work by Bagwell and 
Riordan (1991), their conclusions contrast in three respects with mine. First, they find that informed buyers are not necessary for the signaling of a given quality. Second, uninformative prices occur only when the fraction of informed buyers is intermediate. Third, they don't take into account the monopolist's market power. The main reason for the first result in Bagwell and Riordan (1991) is that higher-quality products entail higher costs of production. In the present paper, higher-quality products do have a higher cost of production, but due to uncontrollable factors such as weather, nature introduces randomness into the quality. This simple fact renders crucial the presence of informed buyers to achieve separation of quality types. The second result mentioned above stems from Bagwell and Riordan's choice of the intuitive criterion (Cho and Kreps, 1987) to prune equilibria. The logic of undefeated equilibria proposed by Mailath, Okuno-Fujiwara and Postlewaite (1993) is proved to provide more intuitive insights in the present case. In particular, this criterion eliminates separating equilibria rather than pooling equilibria, hence informative prices rather than uninformative prices, when uninformed buyers are numerous and prone to believe that quality is high. The idea is that, in such circumstances, it is of no avail to make an effort to fully reveal that quality is high. I believe this result to be noteworthy, although it would be spurned by the intuitive criterion.

\section{Basic model with uninformative prices}

Following Hotelling, I consider an industry in which two differentiated 
goods are located at the two endpoints of the segment $[0,1]$. Buyers do not rank both goods in the same way and their heterogeneous tastes are assumed to be continuously distributed along the segment. The location of a buyer with taste $x$ is interpreted here as his disutility from buying the less-thanideal good located at the left endpoint of the segment (henceforth the left good). The monetary equivalent losses of the buyer $x$ purchasing the left good and the good located at the right endpoint of the segment (henceforth the right good) are $t x^{2}$ and $t(1-x)^{2}$ respectively. The parameter $t$ measures the degree of differentiation between goods and can also be seen as an index for the degree of competition.

The left good is assumed to be an experience good, i. e., quality is not observable to buyers. This good is sufficiently differentiated in taste and/or quality to provide the producer with a monopolistic position, like a FirstGrowth wine in Bordeaux ${ }^{3}$. In contrast, the right good is produced by a competitive fringe of small producers and its quality is perfectly known to buyers. This fits the presence in Bordeaux of numerous wines which are close but imperfect substitutes in taste to a wine classified as First-Growth, and of lower quality too. An immediate consequence of the competition between the producers of the right good is that its price drops to marginal cost of production which I normalize to zero. Hence, the purpose of the present framework is to focus on the monopoly behavior of the producer of the left good

\footnotetext{
${ }^{3}$ Another interpretation could be that a few Bordeaux châteaux among the foremost ones form a dominant cartel or achieve price collusion.
} 
(henceforth the monopolist), using $t$ as an index for the degree of monopoly power. If $t=0$, the taste characteristic becomes irrelevant. If $t$ is positive, the producer of the left good attains some degree of monopoly power.

Moreover, the left good is vertically differentiated in the sense that all buyers agree that higher quality is preferable ${ }^{4}$. The left good is more costly to produce than the right good, hence the superior quality of the left good is partly due to production techniques. Nevertheless, some differences in quality are assumed to be gifts of nature and so are exogenous to the monopolist. The quality of the left good takes one of two values, either high $(H)$ or low $(L)$. The marginal production costs for the left good are constant and equal to $c>0$, regardless of quality. Throughout the paper I shall assume that $L=c$ : this implies that buyers with taste $x<1 / 2$, who exhibit a "personal" preference for the left good, are the only ones to purchase this good when its quality is low and its price is set at marginal cost. Thus, the monopolist is able to "steal" buyers from the competitive fringe of producers only when the quality of the left product is high.

A crucial feature of the markets considered in this article is that information is asymmetric : the monopolist knows the actual quality measured by a quality index $q$, while buyers do not ${ }^{5}$.

\footnotetext{
${ }^{4}$ For the Bordeaux "primeur" release, this amounts to say that the expert predictions of quality are supposed to be infallible and everybody is agreed on them. An extension of the present model has been examined to capture the possibility of expert errors. Results are generally the same as in the present paper except in a particular case, namely when experts are unanimous on quality regardless of whether they are right or wrong.

${ }^{5}$ As far as Bordeaux grands crus are concerned, Di Vittorio and Ginsburgh (1996) stress
} 
The expected utility of a buyer with taste $x$ and income $R$ purchasing the left good is given by $R+q-p-t x^{2}$ if he purchases a good of quality $q$ at price $p$, and $R$ if he does not buy. On the other hand, if the same buyer $(x, R)$ purchases the right good, he obtains the utility $R-t(1-x)^{2}$. I suppose that buyers buy at most one unit of the differentiated good. I also assume that $R$ is large enough for all buyers to find a product for which their utility is positive (in equilibrium). The market is split at the marginal buyer with taste $\widetilde{x} \in[0,1]$ satisfying

$$
R+q-p-t \widetilde{x}^{2}=R-t(1-\widetilde{x})^{2}
$$

This implies a linear demand function $D(p) \equiv \widetilde{x}=(q+t-p) / 2 t$ for the left good, as long as this is non-negative and does not exceed 1. Note that the demand price elasticity $\left|\frac{\partial D(p)}{\partial p} \frac{p}{D(p)}\right|=\frac{p}{q+t-p}$ decreases with the degree of monopoly power.

As the actual quality of the left good is not observable to buyers, they must rely on their beliefs about quality when deciding to purchase the good. The monopolist, in turn, will have to take into account how his choice of price affects the buyers' beliefs. Observing $p$, buyers try to infer some information about quality and update their beliefs. Let $\mu(p)$ denote the buyers' posterior belief that quality is $H$ when the price is $p$. If the buyers assign probability $\mu=\mu(p)$ to the high quality, then $q(\mu) \equiv \mu H+(1-\mu) c$ is the that weather information concerning a whole area is publicly available, while local weather phenomena that mar the grapes, such as hails, remains the château's private information. 
buyers' perception of quality upon seeing $p$ and the monopolist's demand is represented by the demand curve

$$
D(p, \mu)=(q(\mu)+t-p) / 2 t .
$$

Let $\mu_{0}$ be the prior probability assigned to the quality being $H$. This belief is common knowledge : it summarizes all the information that is publicly available in popular quality reports ${ }^{6}$. For instance, it includes information on weather and reputation ${ }^{7}$.

When buyers perfectly identify quality, the monopolist with quality $q$ has a profit function explicitly defined by $(p-c)(q+t-p) / 2 t$. Thus, $\frac{(q-c+t)^{2}}{8 t}$ is the maximum profit he can get by charging his full information price $\frac{q+c+t}{2}$. Clearly, when $q$ or $t$ increase, the left good becomes more differentiated from the right good either in quality or in taste, enhancing the market power of the monopolist who, in turn, raises his price.

When buyers cannot ascertain quality, the monopolist may choose either to fully reveal information on quality through separating prices, or to conceal information through pooling prices. Let us first show the following Lemma.

Lemma 1 When all buyers are uninformed, prices fail to signal quality.

\footnotetext{
${ }^{6}$ In the case of Bordeaux wine, there are numerous guides and reviews such as La Revue du Vin de France, La Lettre du Club Vinophile, the annual "Bordeaux" issue of the Wine Spectator which provides a wine quality index that takes into account factors such as color, aroma, flavour, balance, complexity and aging potential.

${ }^{7}$ Following Landon and Smith (1997), information on the past quality performance of Bordeaux châteaux largely influences the buyers' beliefs on current quality.
} 
Suppose that the price $p$ does reveal high quality. Then the monopolist must not be able to duplicate such a price when his product is of low quality. His demand when doing so would be $D(p, 1)=(H+t-p) / 2 t$, hence he would make a mimicking profit of $(p-c)(H+t-p) / 2 t$, whereas his maximized profit is $\frac{t}{8}$ when quality is perfectly identified. Therefore, to signal the high quality, the price $p$ must satisfy

$$
(p-c)(H+t-p) / 2 t \leq \frac{t}{8}
$$

However, $\frac{t}{8}$ is also the opportunity cost that the high-quality monopolist must bear to reveal quality since it is the highest profit that he can make when he is believed to sell a low-quality product. Thus, the high-quality monopolist finds it profitable to charge an informative price $p$ yielding a profit $(p-c)(H+t-p) / 2 t$, provided that

$$
(p-c)(H+t-p) / 2 t>\frac{t}{8}
$$

This contradicts inequality (2). As in the lemons problem identified by Akerlof (1970), the equilibrium price cannot be informative.

The reason why there is no separating equilibrium is that pricing entails the same cost regardless of quality, that is, namely the monopolist's profit in the absence of informed buyers, $(p-c) D(p, \mu)$, has the same derivative with respect to $p$ for all $q$.

In fact, the high- and low-quality monopolists charge the same price in equilibrium. Given that buyers assign a prior probability $\mu_{0}$ to the high- 
quality monopolist, such a price $p$ must yield a profit no lower than $\frac{t}{8}$, which is what the monopolist could get at best, were he thought to be low-quality, i. e., $(p-c)\left(q\left(\mu_{0}\right)+t-p\right) / 2 t \geq \frac{t}{8}$. Obviously, this inequality holds for infinitely many equilibrium prices.

Nevertheless, some equilibrium prices are less plausible than others. To discard them, it is useful to apply the logic of Undefeated Equilibrium (UE) proposed by Mailath, Okuno-Fujiwara and Postlewaite (1993). Define $\pi_{q}^{*}$ and $\pi_{q}^{\#}$ as the equilibrium profits of the monopolist selling quality $q$ at prices $p_{q}^{*}$ and $p_{q}^{\#}$ respectively. Furthermore, let $\mu^{*}(p)$ be the posterior belief held after observing $p$, that sustains $p_{q}^{*}$ as an equilibrium. Following Mailath, Okuno-Fujiwara and Postlewaite (1993), the equilibrium price $p_{q}^{*}$ survives the UE criterion, provided that there does not exist another equilibrium $p_{q}^{\#}$ "defeating" $p_{q}^{*}$, i. e. :

$$
\text { If } p_{H}^{\#}=p_{L}^{\#} \text {, }
$$

then $\pi_{q}^{\#} \geq \pi_{q}^{*}$ for $q=H, L$ with one inequality strict and $\mu^{*}\left(p_{H}^{\#}\right) \neq \mu_{0}$.

$$
\text { If } p_{H}^{\#} \neq p_{L}^{\#} \text {, }
$$

$$
\text { then } \pi_{H}^{\#}>\pi_{H}^{*}, \pi_{L}^{\#} \leq \pi_{L}^{*} \text { and } \mu^{*}\left(p_{H}^{\#}\right) \neq 1 \text {. }
$$

The existence of such an equilibrium $p_{q}^{\#}$ would induce the monopolist to deviate from $p_{q}^{*}$. Some persuasive arguments in favor of the UE criterion can be found in Mailath, Okuno-Fujiwara and Postlewaite (1993). In the present 
context, the logic of this refinement is parallel to a Pareto dominance argument in reference to the monopolist only. As the monopolist is potentially of two quality types, both of these types should not be wastefully competitive with themselves. In the case without informed buyers, the UE criterion singles out the equilibrium price $\left(q\left(\mu_{0}\right)+c+t\right) / 2=\arg \max _{p}(p-c) D\left(p, \mu_{0}\right)$ simply because it is the equilibrium that Pareto dominates all the other pooling equilibria from the monopolist's viewpoint. Clearly, there does not exist another pooling equilibrium such that requirement (4) is met, hence the monopolist is not tempted to deviate from $\left(q\left(\mu_{0}\right)+c+t\right) / 2$, whatever his quality.

Lemma 2 When all buyers are uninformed, the monopolist charges the uninformative UE price $\left(q\left(\mu_{0}\right)+c+t\right) / 2$.

Lemma 2 states the existence of a lemons problem in the market under consideration, in that the monopolist has no way of signaling quality through price. Such a situation prevailing in the absence of informed buyers will serve as a benchmark to shed light on the role of informed buyers. Furthermore, the only reasonable prediction is that the monopolist will choose the uninformative price $\left(q\left(\mu_{0}\right)+c+t\right) / 2$ which depends on the buyers' prior information about quality. The reason why prices fail to signal quality is that the cost of pricing does not depend on the level of quality. As the incentive to "tell" buyers about quality through price is not higher for a monopolist 
with a high-quality product, mimicry can emerge : the low-quality monopolist charges the same price as his high-quality counterpart, hence prevents buyers from learning the true quality and turns their misinformation to profit.

In the remainder of the article, we shall see that the presence of informed buyers enables prices to signal quality because it lowers the cost of pricing for the monopolist when quality is higher.

\section{The model with informed buyers}

Let us now assume that some buyers can ascertain the quality of the left good. A fraction $I$ of buyers, say the readership of reviews publishing accurate advice on quality, learn the product quality before purchase, while the remaining fraction $1-I$ of buyers believe that quality is high with probability $\mu$. Then the total demand is

$$
\begin{aligned}
\mathcal{D}(p, q, \mu) & \equiv I D(p)+(1-I) D(p, \mu) \\
& =\left(\phi_{q}(\mu)+t-p\right) / 2 t,
\end{aligned}
$$

where $\phi_{q}(\mu) \equiv I q+(1-I) q(\mu), q=H, L$.

The profit of a monopolist selling a product of true quality $q$ at a price $p$, that is believed to be of quality $H$ with probability $\mu$, is now given by $\pi_{q}(p, \mu)=(p-c) \mathcal{D}(p, q, \mu)$. This is a strictly concave function with a single

turning point at $\frac{\phi_{q}(\mu)+c+t}{2}$, which yields a maximized profit of $\frac{\left(\phi_{q}(\mu)-c+t\right)^{2}}{8 t}$.

The presence of informed buyers modifies the framework in a crucial way. From (6), the monopolist's marginal benefit from slightly increasing the price 
can now be expressed as

$$
\frac{\partial \pi_{q}(p, \mu)}{\partial p}=I q / 2 t+((1-I) q(\mu)+t+c-2 p) / 2 t, q=H, L
$$

It is instructive to note that the right-hand side expression depends on $q$ only in the first term. The marginal benefit is higher for a higher-quality monopolist provided that $I>0$. This single-crossing property no longer holds in the absence of informed buyers.

I shall denote by $p_{H}^{I}$ and $p_{L}^{I}$ the separating prices for the high quality and the low quality respectively. The corresponding equilibrium profits will be $\pi_{H}^{I}$ and $\pi_{L}^{I}$. Since the monopolist selling a product of one quality has the option to pretend to sell a product of another quality, the separating prices must satisfy the requirements ensuring that revealing the actual quality is profitable. When quality is perfectly identified, the low-quality monopolist earns more by charging his full information price $\frac{2 c+t}{2}$ than any other price. Thus, $p_{L}^{I}=\frac{2 c+t}{2}$ is the only separating price open to the low-quality monopolist. On the other hand, when the low-quality monopolist is thought to be high-quality after choosing a price $p$, he faces a demand $\mathcal{D}(p, L, 1)$ and has a mimicking profit $\pi_{L}(p, 1)=(p-c)\left(\phi_{L}(1)+t-p\right) / 2 t$. To achieve separation, the high-quality monopolist must set a price $p_{H}^{I}$ that satisfies the condition

$$
\pi_{L}\left(p_{H}^{I}, 1\right) \leq \pi_{L}^{I}
$$

Otherwise, the low-quality monopolist would strictly prefer to spurn $p_{L}^{I}$ and choose $p_{H}^{I}$. Note that the derivative of the mimicking profit in the left- 
hand side of (8) with respect to $p$ decreases with $I$, namely $\frac{\partial^{2} \pi_{L}(p, 1)}{\partial p \partial I}=(c-$ $H) I<0$. In other words, the more informed the market, the more difficult it is fooling buyers. I shall denote respectively by $\mathcal{L}$ the set of prices defined by requirement (8) and by $\bar{p}_{L}^{I}$ the upper root solving the equality version of (8)(see Appendix 1 for more details). The constraint to choose a price in $\mathcal{L}$ to avoid mimicry may distort the price charged by the high-quality monopolist with respect to the full information case, hence creating a signaling cost.

Moreover, if the high-quality monopolist quotes a price $p$ on the basis of which he is believed to sell low quality, then he makes a profit $\pi_{H}(p, 0)=(p-$ c) $\left(\phi_{H}(0)+t-p\right) / 2 t$. Maximizing this profit by setting the price $\frac{\phi_{H}(0)+c+t}{2}$, would give him a profit of $\frac{\left(\phi_{H}(0)-c+t\right)^{2}}{8 t}$. This can be interpreted as the opportunity cost to signal high quality, which increases with the number of informed buyers since $\phi_{H}(0)$ increases with $I$. Thus, the more informed the market, the weaker the incentive to reveal information through price. The separating price $p_{H}^{I}$ must be such that

$$
\pi_{H}\left(p_{H}^{I}, 1\right)>\frac{\left(\phi_{H}(0)-c+t\right)^{2}}{8 t} .
$$

Otherwise the high-quality monopolist would deviate to $\frac{\phi_{H}(0)+c+t}{2}$, no matter what inferences buyers might draw from the observation of such a price. Let $\mathcal{H}$ denote the interval of prices for which condition (9) is met.

In order to reveal quality, the high-quality monopolist must choose a separating price $p_{H}^{I}$ in the set $\mathcal{L} \cap \mathcal{H}$, which turns out to be non empty for all $I>0$ (see the proof in Appendix 2). As a result, informed buyers are 
necessary for the price to be an effective signal of high quality. To state the result in Proposition 1, I define the function

$$
\mathcal{I}(t) \equiv \frac{2 t+H-c}{2(t+H-c)}
$$

where $I=\mathcal{I}(t)$ solves equation $\bar{p}_{L}^{I}-\frac{H+c+t}{2}=0$, that is, $\bar{p}_{L}^{I}$ is equal to the full information price for the high quality product (see Appendix 3 for further calculations). In Figure 3, the function $I=\mathcal{I}(t)$ represents the borderline between the two regions I and II. Proposition 1 states that the monopolist sells both the low- and high-quality products at the full information price for the parameter values in region I, hence, the lemons problem is fully solved due to the presence of informed buyers. On the other hand, the monopolist charges a price exceeding the full information price to reveal high quality for values of $I$ and $t$ in region II. For these values, the presence of informed buyers mitigates the lemons problem since buyers can infer the true quality from observing the monopoly price. Nevertheless, they pay a signaling cost through the price distortion when purchasing the high-quality product.

Proposition 1 Separation is achieved provided that $I>0$. All the revealing prices are defeated by the following pair of least-costly revealing prices :

- $p_{L}^{I}=\frac{2 c+t}{2}$ for the low-quality product,

- and $p_{H}^{I}=\left\{\begin{array}{c}\frac{H+c+t}{2} \text { if } I \geq \mathcal{I}(t), \quad \text { for the high-quality product. } \\ \bar{p}_{L}^{I} \text { otherwise, }\end{array}\right.$

The presence of informed buyers enables prices to signal quality because it lowers the cost of pricing when quality is higher. There is a conflict between 
two effects, due to the presence of informed buyers. First, the mimicking profit, hence the temptation to mimic for the low-quality monopolist, decreases with $I$. Second, the opportunity cost to reveal high quality increases with $I$. However, the former effect dominates the latter for prices inside $\mathcal{L} \cap \mathcal{H}$ : for these prices, the low-quality monopolist does not find it profitable to imitate the price set by the high-quality monopolist. There are now buyers who can ascertain the product quality on the market and, hence, are not fooled. It follows that increasing price has become more damaging to the low-quality monopolist. The price can now function as an effective signal of quality.

There exists a range of prices, namely $\mathcal{L} \cap \mathcal{H}$, at which the high-quality monopolist can profitably distinguish himself. However, from requirement (5), the price entailing the least costly signal defeats all the other revealing prices. Some calculations given in Appendix 3 show that there are two cases to consider, depending on the value of $I$. First, if the fraction of informed buyers is higher than the threshold $\mathcal{I}(t)$, then the full information price for the high quality product, i. e. $\frac{H+c+t}{2}$, is inside $\mathcal{L} \cap \mathcal{H}$, and so will be chosen by the monopolist to signal high quality. When the market is sufficiently well informed, signaling the true quality is possible at no cost. Second, if $I$ is lower than $\mathcal{I}(t)$, signaling the true quality is still possible, albeit at a positive cost for the high quality. In this case, the full information price $\frac{H+c+t}{2}$ does not belong to $\mathcal{L} \cap \mathcal{H}$, thus the high-quality monopolist must distort his price above the full information price to prevent the low-quality monopolist from 
mimicking. By charging $\bar{p}_{L}^{I}$, the high-quality monopolist minimizes the loss of buyers resulting from the upward distortion. The signaling cost incurred by the high-quality monopolist is then measured by the difference $\frac{(H-c+t)^{2}}{8 t}-$ $\pi_{H}\left(\bar{p}_{L}^{I}, 1\right)$, where $\frac{(H-c+t)^{2}}{8 t}$ is the full information profit when the product is of high quality. One can easily check from Appendix 3 that $\bar{p}_{L}^{I}$ decreases with I. The signaling cost declines as the fraction of informed buyers increases, until this fraction reaches the threshold $\mathcal{I}(t)$ above which the signaling cost vanishes and so, too, the lemons problem.

What is the impact of the monopoly power on the signaling activity? From Appendix $3, \bar{p}_{L}^{I}-\frac{H+c+t}{2}$ increases with $t$, meaning that the more market power that the monopolist has, the higher the price distortion to signal high quality. It follows from the single-crossing condition stated in (7) that the lowquality monopolist finds mimicry unattractive whatever his market power. As market power drops, it becomes increasingly costly for the low-quality monopolist to duplicate the high-quality price since demand is more elastic : the more competitive the market, the more damaging the loss of buyers who refuse to buy at a higher price.

The emergence of separating prices due to the presence of informed buyers does not dismiss uninformative prices. Recall that $\mu_{0} \in(0,1)$ is the initial probability assigned by buyers to the high quality. Let $p^{I}$ denote an uninformative price. Since it is the same price charged by the monopolist, regardless of quality, the buyers' posterior beliefs after observing this price are the same 
as their prior beliefs. The monopolist earns $\pi_{q}\left(p^{I}, \mu_{0}\right)$ with the uninformative price $p^{I}$, if such a price does exist. To exist, it suffices that $p^{I}$ satisfies the two following conditions :

$$
\pi_{q}\left(p^{I}, \mu_{0}\right) \geq \frac{\left(\phi_{q}(0)-c+t\right)^{2}}{8 t}, q=H, L
$$

Any price yielding a profit in both states of nature, no lower than the right-hand side of (10) - that is, what the monopolist could get at best if he were thought to be of low quality with certainty -, is a candidate for concealing information. Note that letting the low-quality monopolist mimic is costly for the high-quality monopolist : the loss in profit with respect to the full information situation is given by $\frac{(H-c+t)^{2}}{8 t}-\pi_{H}\left(p^{I}, \mu_{0}\right)$. Moreover, requirement (5) imposes the further restriction on $p^{I}$ :

$$
\pi_{H}\left(p_{H}^{I}, 1\right) \leq \pi_{H}\left(p^{I}, \mu_{0}\right) .
$$

If inequality (11) holds, then the high-quality monopolist is better off with the uninformative price $p^{I}$ than with the separating price $p_{H}^{I}$. Since the low-quality monopolist will also find it more profitable to imitate $p^{I}$ than to reveal information, requirement (11) guarantees that the uninformative equilibrium defeats the least-costly separating equilibrium in the sense of Mailath, Okuno-Fujiwara and Postlewaite (1993). In such a case, it is more plausible that quality will not be revealed in equilibrium. Clearly, if the market is sufficiently well informed so that $I \geq \mathcal{I}(t)$, then (11) is not met since $\pi_{H}\left(p_{H}^{I}, 1\right)=\frac{(H-c+t)^{2}}{8 t}$, which is the full information profit level. But when 
$I<\mathcal{I}(t)$, the returns from signaling high quality with $p_{H}^{I}=\bar{p}_{L}^{I}$ are lower than $\frac{(H-c+t)^{2}}{8 t}$. Thus, (11) will hold for sufficiently high values of $\mu_{0}$. More accurately, let $\bar{\mu}$ define the unique probability $\mu$ such that

$$
\pi_{H}\left(\bar{p}_{L}^{I}, 1\right)=\frac{\left(\phi_{H}(\mu)-c+t\right)^{2}}{8 t}
$$

The right-hand side of (12) is the maximum profit that the high-quality monopolist can make by holding back information, when buyers believe the product to be of high quality with probability $\mu$. The critical value $\bar{\mu}$ is the level of beliefs such that the high-quality monopolist is indifferent between signaling quality at some cost and concealing information about quality. If $\mu_{0}$ is strictly lower than $\bar{\mu}$, then inequality (11) is violated regardless of the uninformative price $p^{I}$ considered. Consequently, it is more plausible that information will be revealed in equilibrium. The result is reversed for values of $\mu_{0}$ higher than $\bar{\mu}$. Then, the monopolist will prefer to conceal his private information about the quality of the product. In Figure $4, \bar{\mu}$ is depicted as a function of $t$ and $I$, for $t \in[0,5], I \in[0,1 / 2]$ and $H-c=1^{8}$. It shows that, given $I, \bar{\mu}$ declines for higher values of $t$. Thus, it is more likely that the monopolist conceals his private information as his market power increases.

Proposition 2 The presence of informed buyers is necessary for price to be an effective signal of quality, but not always sufficient in the following

\footnotetext{
${ }^{8}$ Equation (12) has a unique positive root which has the following expression for $H-c=$ $1:$

$\bar{\mu}=\left[2(I-1)(I+t)+\sqrt{4(I+t)^{2}(1-I)^{2}-4 I(1-I)^{2}(3 I-2)-2 \sqrt{(1-I)(1-I+2 t)}}\right] / 2(1-I)^{2}$.
} 
1. If $I \geq \mathcal{I}(t)$, then separation is achieved at no signaling cost with the full information prices $p_{L}^{I}=\frac{2 c+t}{2}$ and $p_{H}^{I}=\frac{H+c+t}{2}$.

2. if $I<\mathcal{I}(t)$, then

(a) separation is achieved at a signaling cost with the pair of UE prices $p_{L}^{I}=\frac{2 c+t}{2}$ and $p_{H}^{I}=\bar{p}_{L}^{I}$, provided that $\mu_{0} \leq \bar{\mu} ;$

(b) separation fails and a continuum of uninformative UE prices prevails for all $\mu_{0}>\bar{\mu}$.

Proposition 2 summarizes all the results in the model with informed buyers. If the market is well informed, the presence of informed buyers eliminates the lemons problem by increasing the cost of pricing for a lower-quality monopolist so much that mimicking becomes unprofitable (case 1). If the market is poorly informed (case 2), the presence of informed buyers mitigates the lemons problem, provided that buyers' prior beliefs of high quality are sufficiently pessimistic (case 2.a); due, for instance, to bad weather or a bad reputation. In this case, the monopolist must incur a signaling cost to reveal high quality by distorting his price above the full information price. However, optimistic prior belief of high quality when the market is poorly informed (case 2.b) causes separation to fail because signaling the true quality is more costly than accepting mimicry for the high-quality monopolist. 


\section{Conclusion}

This article investigates to what extent the presence of informed buyers permits price to credibly signal quality in markets that are susceptible to a lemons problem. As a general result, informed buyers are necessary but not always sufficient for a monopolist to use prices as signals of product quality, regardless of the monopoly power. The essential effect of the presence of informed buyers is to reduce the benefit accruing to a low-quality monopolist from mimicking his high-quality counterpart. This in turn increases the incentive for signaling high quality through price.

If the market is poorly informed, then the monopolist's price will signal the actual quality provided that buyers a priori hold pessimistic beliefs about high quality. Such beliefs may be due either to unfavorable weather reports or to bad quality performances in the past that have spoilt the monopolist's reputation. Nevertheless, the price is not restored as a signal of quality without entailing some cost. To signal high quality, the price must be distorted above the full information level : the monopolist sacrifices buyers to prove that quality is high. The signaling cost increases with monopoly power. It becomes a too high burden when numerous buyers are uninformed and a priori hold optimistic beliefs on high quality. In such a case, the high-quality monopolist is better off choosing uninformative prices, hence the lemons problem is not overcome.

These results shed light on the lemons problem identified in Figures 1 
and 2. There is evidence that the "primeur" price has never been an effective signal of quality since 1982 for the châteaux under consideration. The most general explanation can be found in Spence (1976) : "For a signal to be effective, it must be unprofitable for sellers of low quality products to imitate it". Obviously, the cost of using "primeur" price as a signal of quality is the same for the four Médoc châteaux endowed with different qualities. The main insight that the present analysis adds is that the market is poorly informed and buyers a priori hold optimistic beliefs about the quality offered by the four châteaux. The high reputation of the four châteaux may explain why uninformed buyers unrealistically believe quality to be high before purchase. That the market is poorly informed means that either few buyers rely on expert opinion or few buyers develop sufficient skills to estimate the true quality. This is consistent with two empirical studies on the Bordeaux wine industry : Landon and Smith (1997) find no evidence that buyers use expert predictions when purchasing Bordeaux wine and Ashenfelter and Jones (1998) argue that expert opinion neglects some information that is useful in making predictions, such as weather data.

The explanation above as to why some châteaux are better off charging uninformative "primeur" prices does not exhaust the subject. Further research is necessary to determine whether the practice of concealing information obeys insurance motives or serves as a coordinating device in a situation of repeated competition. Moreover, it may be instructive to extend the present 
analysis by considering that the Bordeaux "primeur" release has the features of forward trading. A model along this line can be found in Mahenc and Meunier (2003). This work exhibits forward pooling equilibria which can be here interpreted as follows : low-quality producers earn positive speculative profits by selling forward at "primeur" prices that are both uninformative and upward-distorted, while high-quality producers need uninformative "primeur" prices to reduce the cost of signaling quality on the market of bottled-wine.

\section{Appendix}

Appendix 1. The set $L$

Requirement (8) can be rewritten

$$
\left(p_{H}^{I}-c\right)\left(\phi_{L}(1)+t-p_{H}^{I}\right) / 2 t-t / 8 \leq 0,
$$

which holds only for prices $p_{H}^{I}$ in the set

$$
\begin{aligned}
& \mathcal{L} \equiv\left[c,\left(\phi_{L}(1)+c+t-\sqrt{\left.\phi_{L}(1)+c+t\right)^{2}-4 c\left(\phi_{L}(1)+t\right)-t^{2}}\right) / 2\right] \\
& \cup {\left[\left(\phi_{L}(1)+c+t+\sqrt{\left(\phi_{L}(1)+c+t\right)^{2}-4 c\left(\phi_{L}(1)+t\right)-t^{2}}\right) / 2, H+t\right], \text { where } } \\
& \bar{p}_{L}^{I} \equiv\left(\phi_{L}(1)+c+t+\sqrt{\left(\phi_{L}(1)+c+t\right)^{2}-4 c\left(\phi_{L}(1)+t\right)-t^{2}}\right) / 2 \\
&=(H-I(H-c)+c+t+\sqrt{(H-c)(1-I)((H-c)(1-I)+2 t)}) / 2 .
\end{aligned}
$$

Appendix 2. The set $H$

Condition (9) can be rewritten

$$
\left(p_{H}^{I}-c\right)\left(H+t-p_{H}^{I}\right) / 2 t-\left(\phi_{H}(0)-c+t\right)^{2} / 8 t>0 .
$$

This inequality is met for prices $p_{H}^{I}$ in the interval

$$
\mathcal{H} \equiv\left(\left(H+c+t-\sqrt{(H+c+t)^{2}-\left(\phi_{H}(0)-c+t\right)^{2}-4 c(H+t)}\right) / 2,\right.
$$




$$
\begin{aligned}
& \left.\left(H+c+t+\sqrt{(H+c+t)^{2}-\left(\phi_{H}(0)-c+t\right)^{2}-4 c(H+t)}\right) / 2\right) \\
& \quad=((H+c+t-\sqrt{(H-c)(1-I)((H-c)(1+I)+2 t)}) / 2, \\
& (H+c+t+\sqrt{(H-c)(1-I)((H-c)(1+I)+2 t)}) / 2) .
\end{aligned}
$$

It follows that, for all $I>0$,

$$
\begin{aligned}
& \bar{p}_{L}^{I}=(H-I(H-c)+c+t+\sqrt{(H-c)(1-I)((H-c)(1-I)+2 t)}) / 2 \\
& <(H+c+t+\sqrt{(H-c)(1-I)((H-c)(1+I)+2 t)}) / 2 .
\end{aligned}
$$

Thus, for all $I>0$, the set $\mathcal{L} \cap \mathcal{H}$ is non empty.

Appendix 3. The price distortion for high quality

The price distortion to reveal high quality can be expressed as follows

$$
\bar{p}_{L}^{I}-\frac{H+c+t}{2}=(-I(H-c)+\sqrt{(H-c)(1-I)((H-c)(1-I)+2 t)}) / 2 .
$$

It can be seen that this distortion decreases with $I$ and increases with $t$.

Moreover, straightforward calculations give that $\bar{p}_{L}^{I}-\frac{H+c+t}{2} \leq 0$ for all $I \geq \mathcal{I}(t)$. 


\section{Références}

[1] AKERLOF, G. A. (1970), "The Market for 'Lemons' : Qualitative Uncertainty and the Market Mechanism", Quarterly Journal of Economics $84,488-500$.

[2] ASHENFELTER, O. and G. JONES (1998), "The Demand for Expert Opinion : Bordeaux Wine", working paper, presented at the 6th Annual Meeting of the Vineyard Data Quantification Society, October 2-3, 1998.

[3] BAGWELL, K. and M. H. RIORDAN (1991), "High and Declining Prices Signal Product Quality", American Economic Review 81, 224239.

[4] CASON T. N. and L. GANGADHARAN. (2002), "Environmental Labelling and Incomplete Consumer Information in Laboratory Experiments", Journal of Environmental Economics and Management 43, 113-134.

[5] CHO, I-K. and D. KREPS. (1987), "Signaling Games and Stable Equilibria", Quarterly Journal of Economics 102, 179-221.

[6] DI VITTORIO, A. and V. GINSBURGH (1996), "Des Enchères comme Révélateurs du Classement des Vins", Journal de la Société Statistique de Paris 137, 19-49.

[7] KARL H. and C. ORWAT. (1999), "Economic Aspects of Environmental Labelling" in Yearbook of Environmental and Resource Economics 
1999/2000 (H. Folmer and T. Tietenberg, Eds.), Elgar, Cheltenham, UK, 107-170.

[8] LANDON, S. and C. E. SMITH (1997), "The Use of Quality and Reputation Indicators by Consumers : The Case of Bordeaux Wine", Journal of Consumer Policy 20, 289-323.

[9] MAHENC, P. and V. MEUNIER (2003), "Forward Markets and Signals of Quality", Rand Journal of Economics, forthcoming.

[10] MAILATH, G., M. OKUNO-FUJIWARA and A. POSTLEWAitE (1993), "Belief-Based Refinements in Signaling Games", Journal of Economic Theory 60, 241-276.

[11] MILGROM P. and J. ROBERTS (1986), "Price and Advertising Signals of Product Quality", Journal of Political Economy 94, 796-821.

[12] NELSON, P. (1974), "Advertising as Information",Journal of Political Economy 82, 729-754.

[13] SPENCE, A. M. (1973), "Job Market Signaling”, Quarterly Journal of Economics 85, 355-379.

[14] SPENCE, A. M. (1976), "Informational Aspects of Market Structure : An Introduction", Quarterly Journal of Economics 90, 591-597. 


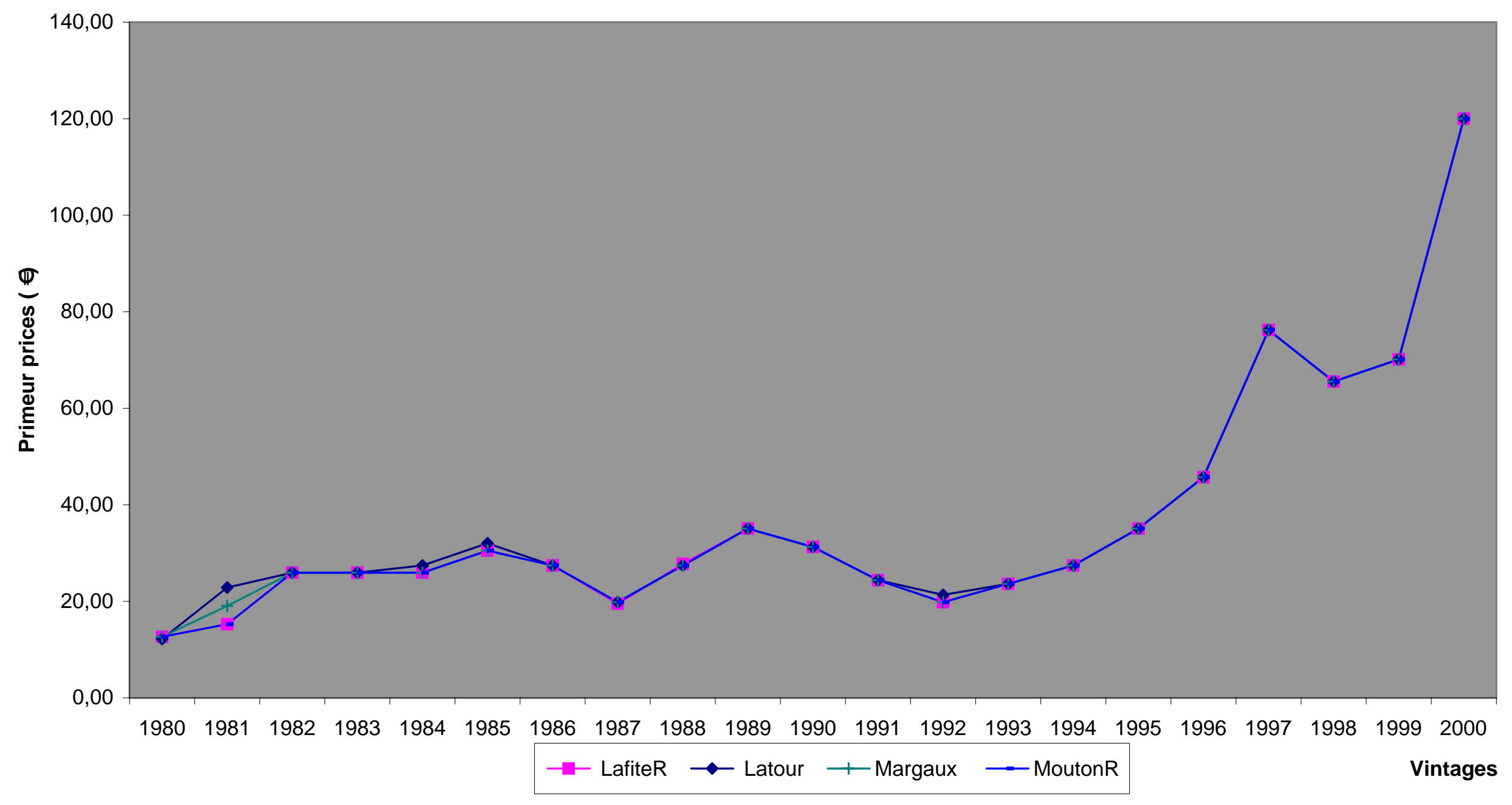

Figure 1. Primeur prices of 4 Médoc grands crus 


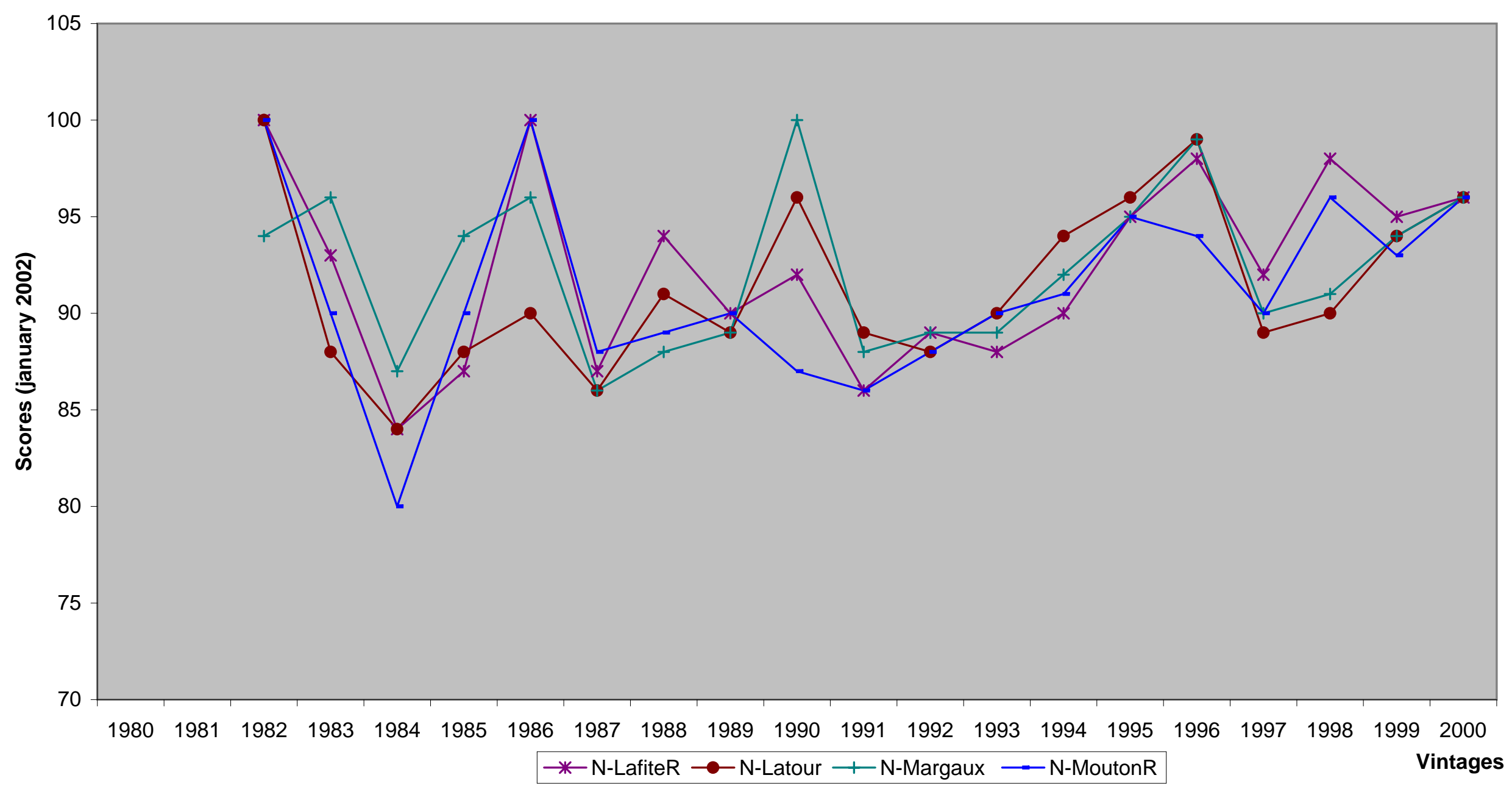

Figure 2. Parker's scores for 4 Médoc grands crus 


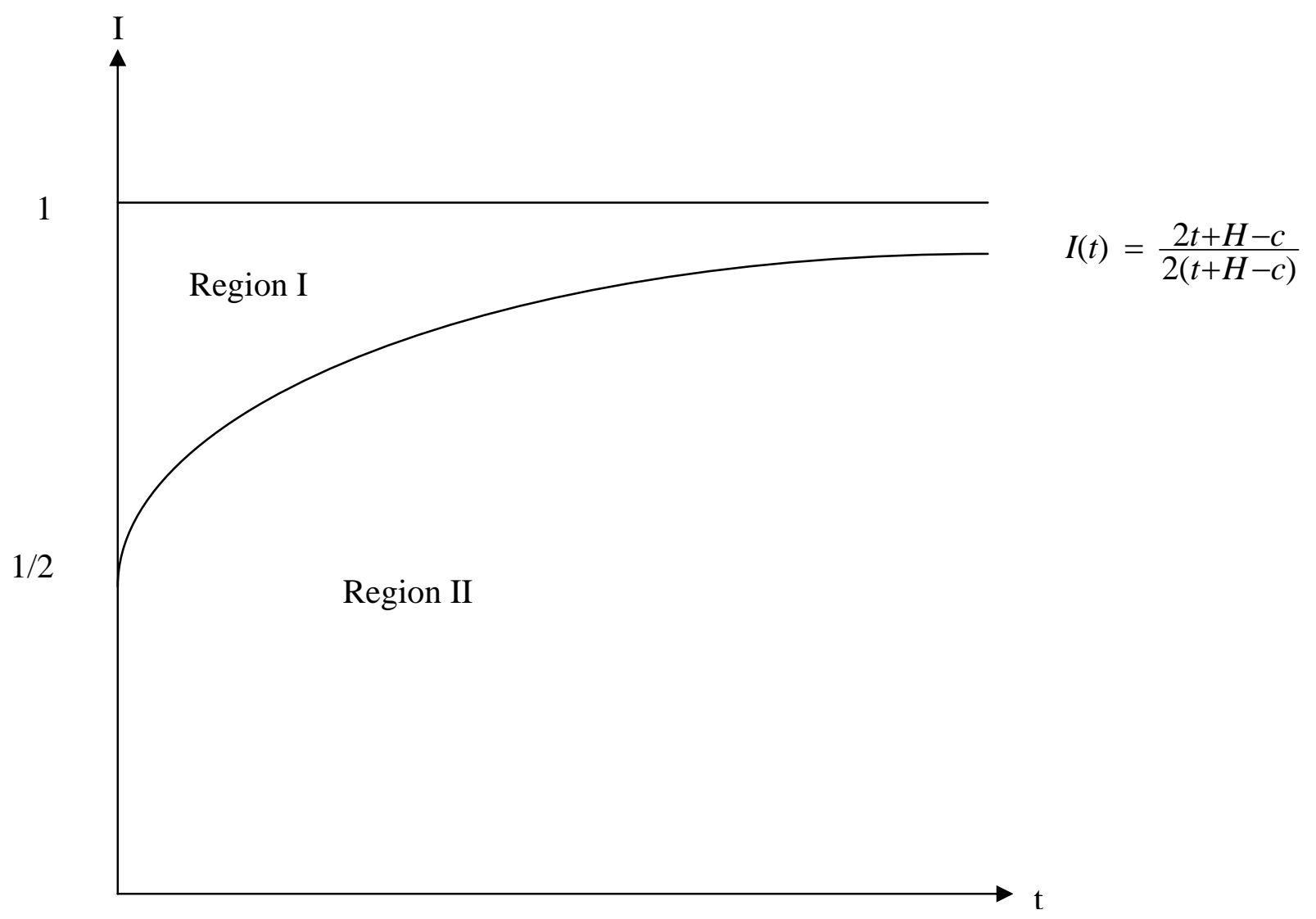

Region I : no price distortion

Region II: price distortion

Figure 3. Parameter values for price distortion 